\title{
Research on College English Autonomous Learning Strategies Based on the Digital Instructional Platform*
}

\author{
Wanli Zhao \\ School of Foreign Languages, Xianyang Normal University, 712000, China
}

\begin{abstract}
Under the digital network environment, one of the objectives of college English teaching is to cultivate students' autonomous learning ability and make students become lifelong learners. The purpose of this paper is to investigate the current situation of college English autonomous learning strategy use based on the digital instructional platform. Through questionnaire and interview, it is found that the digital learning environment is not so good, and the use of learning strategies is not satisfactory in some degree, especially metacognitive strategy, affective strategy and social strategy. The following suggestions are put forward: strengthen the training of autonomous learning strategies, improve teachers' educational technology literacy, network environment, perfect the teaching management, and improve teachers' educational technology literacy and students' information literacy.
\end{abstract}

Index Terms-autonomous learning strategies, college English, digital instructional platform

\section{INTRODUCTION}

In July 2007, the national ministry of education promulgated College English Curriculum Requirements, which explicitly proposes to enhance students' autonomous learning ability, improve the comprehensive cultural quality; change from teacher-centered teaching mode to student-centered; cultivate the students' lifelong learning ability as the guidance of lifelong education. Students' autonomous learning ability has become the focus of college English teaching. A person needs to have the ability of autonomous learning, and lifelong learning will be the inevitable trend of social development. Whether a person has the autonomous learning ability has become an important sign to measure a person's quality.

Modern education has realized that the basic purpose of education is to make students become independent, autonomous and effective learners. Therefore, strengthening the cultivation of college students' learning strategies and helping them grasp effective learning strategies aim at cultivating students' autonomous learning ability, which can make them acquire new knowledge and explore new problems. Autonomous learning strategies can stimulate students' learning initiative and enthusiasm effectively and it can also improve their autonomous learning ability and learning efficiency (Li, 2007). There are three significances of autonomous learning strategies. Firstly, it can improve students' learning and learning efficiency in a large scope, especially it can promote and improve the students who are with learning difficulties because of intelligence or other objective factors, to a certain extent, it can help them reduce the learning disabilities and increase self-confidence in learning. Secondly, autonomous learning strategies can guide the teachers' teaching more effectively. Objective and meaningful learning strategy teaching reduces the teaching and training time. That is to say, it can release the burden of students' learning. Thirdly, it is benefit for new curriculum reform. In the information age, the individual is limited on the master of subject knowledge, whereas grasping the strategy of knowledge acquisition contributes to grasp more knowledge.

The digital teaching platform provides convenience for students' autonomous learning in the choice of resources, selection of space, the development of the learning style, learning evaluation, which undoubtedly provides more advantages for students to develop college English autonomous learning. But through investigation it is found that the current situation of college English autonomous learning is not very satisfactory. Quite a number of students lack awareness of the college English autonomous learning strategies and their application. Therefore, how to take advantage of digital teaching environment to achieve self-learning ability is a problem to be a concern.

\section{LITERATURE REVIEW}

Modern education has realized that the basic purpose of education is to make students become independent, autonomous and effective learners. Therefore, it is so important to cultivate students' consciousness of autonomous learning and English learning strategy.

\footnotetext{
* Fund: This paper is one of the research results of Shaanxi Province education scientific "Twelfth Five-Year Plan" Project (SGH12376), Xianyang Normal University Teaching Reform Project (201202013), and Center for Linguistics and Applied Linguistics of Guangdong University of Foreign Studies (12CLAL009).
} 


\section{A. Core Concepts}

\section{Autonomous Learning}

"Autonomous learning" is put forward based on "passive learning", "mechanical learning" and "learning from others" (Dickinson, 1992). Since the 1950s, autonomous learning has become an important research topic of educational psychology. By the 1980s, Holec firstly introduces autonomous learning theory to the field of foreign language teaching. Holec (1981) thinks that autonomous learning is "taking charge of their own learning ability", which includes the establishment of learning goals, self-monitoring and self-evaluation. There have been a number of researchers proposing understanding of "autonomous learning" from different aspects. Little (1990) considers that autonomous learning is the learners' psychological reaction to learn the content and process. In autonomous learning, attitude and ability are the key factors to determine the autonomous learning. Pintrich (2000) thinks that learning is an active, constructive learning process. Students determine learning goals by themselves and monitor cognition, motivation and behavior which are constrained by the target and contextual features. Barry J. Zimmerman (2011) thinks that Self-regulated learning (or self-regulation) refers to the process whereby learners personally activate and sustain cognitions, affects, and behaviors that are systematically oriented toward the attainment of learning goals.

Chinese scholar Pang Weiguo (2003) argues that the basic characteristics of the autonomous learning are initiative, independence, effectiveness and relativity. After studying definitions of foreign scholars, Shu Dingfang (2004) reduces the English autonomous learning system to three aspects: attitude, capacity, and environment. Pang Weiguo believes that the initiative is one of characteristics of autonomous learning whereas Shu Dingfang attaches importance to the attitude of autonomous learning. As can be seen, learners' high sense of ownership in the process of autonomous learning is the most important feature of autonomous learning. Autonomous learning is not completely learning freely, but students are responsible for their own learning under the guidance of teachers, which is the meaning of autonomous learning in this study.

2. Language learning strategies

Learning strategies in this paper refer to the strategies that people take to help to master the language in the process of learning a foreign language. Many scholars abroad have given the different definitions. Rubin (1975) defines the language learning strategies as "the techniques or devices which a learner may use to acquire knowledge." Stern (1983) defines it as "particular forms of observable learning behavior, more or less, consciously employed by the learner", Oxford (1990) defined as "specific actions taken by the learner to make learning easier, faster, more enjoyable, more self-directed, more effective, and more transferable to new situations". In addition to the definitions above, many scholars have given the definitions of their own. English learning strategy is a combination of learning skill and learning technology. It is also the learners' learning plan consisted of rules and language learning skills. The core of English autonomous learning strategies is self exploration, self discovery, which focus is how to help students learn the language and skills.

\section{Digital instructional platform}

Digital teaching refers to teaching activities in the digital environment, in which teachers follow the rules of modern education theories, and use the digital teaching resources to cultivate students with the digital mode to satisfy the needs of the new century. The digital instructional platform based on network teaching software offers comprehensive support to different level students' personalized learning. It can achieve new learning style, realize the personalized teaching activity and promote the sharing and utilization of the teaching resources. It has the following advantages to English learners: provide more practice opportunities, create a real language learning environment, and improve students' listening and speaking skills. Through computers and network, learners can fully reflect their initiative. In the digital environment, teachers' main task is not only how to teach better, but how to use the digital environment to cultivate learners' autonomous learning ability. Students are not dependent on the teacher's teaching and textbook, but utilize the digital platform and resources to carry out autonomous learning.

\section{B. Theoretical Foundation}

Autonomous learning is not a teaching method, but a way students use to build their own knowledge spontaneously and autonomously, which mainly has the following theoretical foundations: constructivism, humanism and metacognitive theory.

One of the most influential representatives of constructivism is the famous Swiss scholar Piaget. Constructivism holds that knowledge acquisition is not taught by teachers but learnt by learners, which emphasizes that teachers are the helpers and promoters instead of imputers of knowledge (Fan, 2010). In certain conditions, learners gain knowledge by using the necessary learning materials and constructing mode with the help of teachers and partners. It advocates that in the process of construction, teachers should not only require students to collect and analyze relevant information, and then seek answers actively, but also encourage students to be responsible for their own learning and help students form their own learning strategies. Only in this way can they have the ability to adjust their own learning strategies constantly.

The main representatives of the learning theory of humanism are Maslow and Rodgers, who believes that the ultimate goal of teaching is to make people become free and independent people, become assertive with strong adaptability and distinct personality (Liu, 1999). Humanism learning theory's "people-oriented, student-centered" 
teaching philosophy emphasizes students' independent position in the study, and the importance of learners participating in the learning process actively, which is the core and foundation of autonomous learning. In the teaching process, teachers provide learners sufficient space, encourage them to participate in the study initiatively and form the good habit of autonomous learning.

Metacognition is the subject of cognition of self awareness and self monitoring, which consists of metacognitive knowledge, metacognitive experience and metacognitive monitoring. Metacognitive knowledge, the key to students from "learn" to "learn", is the prerequisite for success in learning. Metacognitive experiences change the knowledge structure of textbooks into cognitive structure of students, and make students become subjective from consciousness to behavior, which is advantageous to the student's main body status. Metacognitive monitoring is that cognitive subject controls cognitive activity initiatively, and chooses learning strategies flexibly.

\section{Researches on English Learning Strategies at Home and Abroad}

Foreign language learning strategy research has experienced the following four stages. Firstly, initial stage (in the mid-1970s to mid-1980s). In 1975, Rubin published a paper entitled What the Good Learner can Teach Us on TESOL, in which Rubin classified learners' strategies into three categories: psychological characteristics of learners, learners' social strategies and cognitive strategies. In 1981, Rubin classified the learning strategies into direct learning strategies and indirect learning strategies. USA scholar Rebecca L.Oxford classified direct learning strategies into memory strategies, cognitive strategies and compensation strategies; the indirect strategies into metacognitive strategies, affective strategies and social strategies. Researches of this period focus on the description, definition and classification of good language learners' strategies. Secondly, Prosperity and development stages of language learning strategy (in the late 1980s to mid-1990s). In 1987, the Wenden and Rubin compiled a collection of essays together, named Learners' Strategies of Learning a Second Language including 12 papers, among which Wenden (1982, 1986) defined meta cognitive strategies, who pointed out that metacognition strategies are a more advanced and independent strategy system with cognition activities. Metacognitive strategies' function is to plan, monitor and evaluate the cognition activity and behavior. Thirdly, mature stage of language learning strategies (in the 1990s). During this period, there are large numbers of researches on learning strategies and learning strategy training methods. In 1990, Rebecca L.Oxford published Language Learning Strategies, in which Rebecca L.Oxford put forward a more comprehensive system of two language learning strategies classification system SILL (Strategy Inventory for Language Learning), based on previous studies of skill and all micro strategies. This learning strategy is widely used and approved later in the academic filed. O'Malley and Chamot lead information processing theory and cognitive theory to second language learning strategies, who think language learning is a dynamic process of skill acquisition. In 1990, O'Malley\& Chamot punished Learning Strategies in Second Language Acquisition, which marked the second language learning strategy research has reached a new level. Fourthly, introspection and further development stage of language learning strategy (in the late 1990s to now). In the late 1990s, researchers began to focus on the study of learning strategy training. Oxford (1990) believed that language learning strategy training can make students use appropriate learning strategies more consciously. O'Malley and Chamot (1994) believed that a lot of learning strategy trainings can promote learning strategy program and internalization.

Chinese scholars started later on the study of second language learning strategies. In 1987, Huang Xiaohua with her supervisor finished a paper whose title is Learning Strategies in Oral Communication, which marks the beginning of English learning strategies in China. The domestic research of learning strategies is divided into three stages: the first stage $(1990 \sim 1995)$ is to draw lessons from abroad and make an introduction; the second stage (1996 1999) is the innovation and development; the third stage (2000 - present) is a rapid development and expansion stage. Here a total of more than 40 papers were published in major publications. At the same time there are a lot of book published. English learning strategy theory written by Wen Qiufang has a far-reaching influence on the later research. In 2002, Cheng Xiaotang and Zheng Min compiled and published English learning strategy that adapts to the requirement of the new curriculum standard and specializes for the primary and secondary school teachers training, which is a simple and practical training teaching material.

Second language learning strategy research has made great achievements both at home and abroad, but there is still a lot of room to develop whether from the breadth or depth at home. Through questionnaire and interview, the paper mainly investigates the current situation of English autonomous learning strategy based on digital instructional platform in normal universities.

\section{RESEARCH DESIGN}

\section{A. Research Purpose and Objects}

In order to investigate the current situation of college English autonomous learning strategy use based on the digital instructional platform and explore its restrictive factors, this paper selected college English network teaching system of Xianyang normal university as a case study to investigate the use of English autonomous learning strategies.

The study objects were non-English major full-time undergraduates in Grade 2012 and 2013, college English teachers and management staff of the network platform. 160 questionnaires were given out to students and 156 were taken back. 


\section{B. Research Methods}

\section{Questionnaire}

This questionnaire is divided into two parts, the first part of which is revised from Oxford learning strategies questionnaire, including memory strategy, cognitive strategy, compensation strategy, metacognitive strategy, affective strategy and social The Likert-type scale is used in the first part, that it is to say, $1=$ Never or almost never true of me; $2=$ Usually not true of me; $3=$ Somewhat true of me; $4=$ Usually true of me; $5=$ Always or almost always true of me. The second part is the open questionnaire which needs to be answered.

\section{Interview}

The purpose of interview is to make some problems clear, which are not directly investigated in questionnaire, including the attitude of students, teachers and network administrators using the network platform; difficulties of students using internet platform; concepts of teachers' guidance as well as teachers' problems and difficulties in network teaching counseling etc. Nine students, five teachers and two network administrators participated in the interview, which had face to face interview and telephone interview.

\section{ANALYSIS AND DISCUSSION}

\section{A. Analysis and Discussion of Questionnaire}
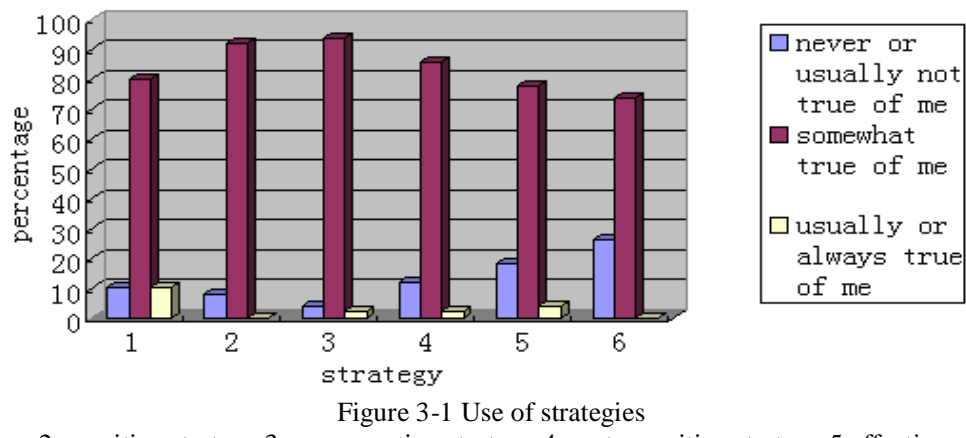

Note: 1 Memory strategy 2. cognitive strategy 3 .compensation strategy 4. metacognitive strategy 5 .affective strategy 6 .social strategy

Memory strategy is a series of ways that students use to remember things. From Figure 3-1 above, it is shown that $10 \%$ students never use memory strategy, $80 \%$ students use memory strategy sometimes, and $10 \%$ students always use it in learning English. Cognitive strategy indicates that students solve and treat learning materials in all kinds of ways. We know that about $92 \%$ students used cognitive strategy in different degrees and about $8 \%$ students did not use it, which suggests that they are not good at using cognitive strategies and they are not positive at learning English. When students have difficulty in learning English, they usually use compensation strategy which is a kind of behavior that students use to remedy disadvantages of language knowledge. It is found that about $92 \%$ students use compensation strategy in different ways and about 4\% students don't apply it to learning English while another 4\% students use it more often. Meta-cognitive strategy is one kind of behavior that students manage, monitor and evaluate learning process by themselves. It is found that $86 \%$ students use it more or less, $12 \%$ students never use it, while only 2 students always use it. Affective strategy is a kind of psychological strategy which students put into use to help themselves to control emotion, overcome anxiety and strengthen interests and confidence in learning English. The result of research indicates that about 78\% students use affective strategy more or less in learning English, while 18\% students never use it, only $4 \%$ students always use it. Students develop language communication skills by learning social norms of target language culture, which means social strategy. The data shows that $26 \%$ students do not use social strategy, $74 \%$ students use it sometimes. No one always uses it.

In the questionnaire, the following 6 items designed are related to students' autonomous learning: I often review English text (2.5\%); I use English in all kinds of ways (5\%); I try my best to find ways to learn English well (28.8\%); I make plans to ensure enough time to learn English (18\%); I have clear goal to improve my English (20\%); I think about my progress in learning English (35\%). These data shows that students don't have positive attitude to learn English. Compensation strategy is used more than others in the six strategies, while affective strategy is used less.

\section{B. Analysis and Discussion of Interview}

Five teachers interviewed think that they need training in network teaching skills, and the biggest obstacles of students autonomous learning monitoring are poor network operation, and lack of incentives for students to learn English autonomously. Two network administrators think that autonomous learning equipment is often needed to be repaired; utilization of autonomous learning platform is not high.

Nine students whose performances are in different level in their class were chosen to do interview. For example, when asked if they had the habit of previewing English before class and what help they need to finish preview, the top student said: "I have the habit of preview and I think it is so important to do it to learn English well. When I am in 
trouble, I will try my best to solve it with materials in hand. If it is impossible, I will mark it clearly and listen to teacher carefully or ask help for teachers"; the medium range student said: "I sometimes do the preview. When I am in trouble, I usually consult it with materials in hand"; the lower range student said: "My English is not good and previewing English makes me sad. I think it is a way of wasting time." All of the students want to communicate with foreigners when they meet them in daily life, but they can only say hello to them because of poor spoken English. When asked what the biggest difficulties and problems are in digital network learning, they gave the following response: they are not familiar with the function of the network teaching platform and can't operate well; the teaching equipment should be improved; counseling time should be increased; teaching and learning resources should be rich.

\section{Results and Suggestions}

Based on the analysis of questionnaire and interview above, it is found that students are relatively good at using compensation strategy, and then cognitive strategy, while they need to strengthen memory strategy, metacognitive strategy, affective strategy, social strategy, especially metacognitive strategy. The network learning environment is not satisfying, including equipment, resources, teachers etc. The following suggestions are put forward.

1. Strengthen the training of autonomous learning strategies

Firstly, we should cultivate students' memory strategy. With the development of society, traditional ways of learning English words can not satisfy the needs of information. Large vocabulary is essential to learn English well, so students can use different ways to memory words, such as classification of induction which means that students can remember words by using its characteristics such as prefix, suffix, antonym, synonym and so on. Secondly, students should strengthen the ability of mastering metacognitive strategy. They had better make a learning plan according to his/her existing knowledge foundation. During the learning process students should realize self monitoring by asking himself/herself questions and recording his/her learning. They should evaluate their learning with classmates or teachers at fixed period. Teachers should encourage students to ask others for help when they are in trouble; teachers can praise or blame students properly according to his/her performance well done or not. Mastering metacognitive is the key to realize autonomous learning. Finally, students' will should be strengthened by developing social affective strategy. In the interview, most students dare not communicate with foreigners because they are afraid of making mistakes. To release the situation, there are some suggestions. (1) In class, teachers should encourage students to ask and answer questions in English. Whether it is right or wrong, teachers should show appreciation. (2) Teachers encourage students to use body language to express their feelings. (3) Building an English corner. Every week, students can communicate their thoughts with classmates or teachers here. Students may say whatever they want as long as they say it in English. For a long time, they are used to thinking things and saying it freely in English. In all, it is helpful for learners to make use of English learning strategies.

2. Improve the network environment

A full range of learning conditions should be provided for students. Insufficient learning equipment is the important factors that limit autonomous learning, such as lack of autonomous learning classroom, outdated equipment, few net branches, etc. In the short term, it is maybe difficult to change the present situation. It is hoped to extend the open hours of autonomous learning classrooms and provide more internet cables in the library, student dormitories to facilitate students to learn independently.

3. Perfect the teaching management

School of foreign languages should be in combination with the practical situation and formulate suitable web-based English autonomous learning plan according to the course requirements. Establish and improve the network teaching management system to achieve English network teaching goals, put forward the functional requirements and assessment criteria, clarify the responsibilities of the teaching management staff at all levels and the mutual relationship. The network teaching of English teachers should be quantified. Draw up multi-level and multi-type learning evaluation index, online English learning should be brought into the credit system management.

4. Improve teachers' educational technology literacy

Promote the development of teachers' network practical knowledge. The formation of network autonomous learning atmosphere is a key to improve teachers' education technology literacy. Update teachers' concepts, refresh teachers' roles, improve teachers' network teaching monitoring ability and network teaching behaviors.

5. Improve students' information literacy

When teachers cultivate students' metacognitive strategy, they can recommend students to use information tools which can promote their metacognitive strategy, such as electronics, web logs, self test tools, etc. Students can be conducted to set up their learning autonomy from the following aspects: strengthen students' independent consciousness, clear goals of college English network learning and establish a system of autonomous learning cooperative group.

\section{CONCLUSION}

College English curriculum requirements explicitly proposes to enhance students' autonomous learning ability, and the digital teaching platform provides convenience for students' autonomous learning. However, in the six learning strategies of this study, it is found that the use of learning strategy is not satisfactory in some degree except for compensation strategy, especially meta-cognitive strategy, affective strategy and social strategy. Network learning 
environment is not so good because of some problems which partly come from students, teachers, net equipment, administrators, etc. So, the following suggestions are put forward: Strengthen the training of autonomous learning strategies, improve teachers' educational technology literacy, network environment, perfect the teaching management, and improve teachers' educational technology literacy and the students' information literacy. But sometimes it is difficult to put the system of cultivating college students English learning strategies into effect. It is hoped that more scholars pay attention to and do the research on autonomous learning strategies under digital instructional platform.

\section{REFERENCES}

[1] Barry J. Zimmerman , Dale H. Schunk . (2011). Handbook of Self-Regulation of Learning and Performance. London: Routledge.

[2] Cheng Xiaotang, and Zheng Min. (2002). English Learning Strategies. Beijing: Foreign Language Teaching and Research Press.

[3] Dickinson, L. (1992). Learner Autonomy 2: Learner Training for Language Learning. Dublin: Authentic.

[4] Fan Fuping. (2010). Theory of Constructivism and Higher Vocational English Self-study. Journal of Yellow River Water Conservancy Vocational and Technical College, 22, 77-80.

[5] Heloc. 1981. Autonomy and Foreign Language Learning. Oxford: Pergamon Press.

[6] Huang Xiaohua. (1987). Learning Strategies in Oral Communication. Applied linguistics, 8, 287-304.

[7] Li Bingbing. (2007). Study on English Learning Strategies and Autonomous Learning Ability. Hubei Today, 2, 65-72.

[8] Little, D. (1990). Autonomy in Language Teaching. London: C.I.L.T.

[9] Littlewood, W. (1999). Defining and developing autonomy in East Asian contexts. Applied Linguistics, 1, 71-94.

[10] Liu Xuanwen. (1999). Humanism Teaching View of Rodgers. Journal of Zhejiang Normal University, 2, 81-83.

[11] O’Malley, J. M. \& Chamot, A. V. (1990). Learning Strategies in Second Language Acquisition. Cambridge: Cambridge University press.

[12] Oxford, R. (1990). Language Learning Strategies: What every teacher should know. Rowley, Mass.: Newbury House.

[13] Pang Weiguo. (2005). Autonomous Learning-Theory and Strategy of Learning and Teaching. Shanghai: East China Normal University Press.

[14] Pintrich. (2000). Handbook of self-regulation. San Diego: Academic Press.

[15] Rubin J. (1975). What the Good Learner can Teach Us. TESOL Quarterly, 9, 41-51.

[16] Shu Dingfang. (2004). Foreign language teaching and reform: problems and countermeasures. Shanghai: Shanghai foreign language education press.

[17] Stern, H. H. (1983). Fundamental Concepts of Language Teaching. Oxford: Oxford University Press.

[18] Wenden, A. (1991). Learner Strategies for Learner Autonomy. New York: Prentice Hall.

[19] Wen Qiufang. (1996). English Learning Strategies. Shanghai: Shanghai Foreign Language Education Press.

[20] Xu Jinfen. (2004). A survey and analysis of non-English major undergraduates' autonomous English learning competence. Foreign Language Teaching and Research, 1, 64-68.

Wanli Zhao was born in Xianyang, China in 1970. She received her Ed.M degree in English from Shaanxi Normal University, China in 2001.

She is currently an associate professor in the School of Foreign Languages, Xianyang Normal University, Shaanxi, China. Her research interests include college English Autonomous Learning and English teacher competency. 